\title{
An Efficient Green Procedure for Synthesis of Some Fluorinated Curcumin Analogues Catalyzed by Calcium Oxide under Microwave Irradiation and Its Antibacterial Evaluation
}

\author{
S. Elavarasan, D. Bhakiaraj, T. Elavarasan, and M. Gopalakrishnan \\ Synthetic Organic Chemistry Laboratory, Department of Chemistry, Annamalai University, Annamalainagar, \\ Tamil Nadu 608 002, India \\ Correspondence should be addressed to M. Gopalakrishnan; profmgk61@gmail.com
}

Received 15 May 2013; Accepted 25 July 2013

Academic Editor: Maolin Guo

Copyright (C) 2013 S. Elavarasan et al. This is an open access article distributed under the Creative Commons Attribution License, which permits unrestricted use, distribution, and reproduction in any medium, provided the original work is properly cited.

\begin{abstract}
A series of fluorine substituted curcumin analogues have been synthesized in a cheaper and greener method using calcium oxide as catalyst under microwave irradiation. All the synthesized compounds have been characterized by FT-IR, MS, elemental analysis, and ${ }^{1} \mathrm{H}$ and ${ }^{13} \mathrm{C}$ NMR spectroscopic techniques and screened for antibacterial activities against Staphylococcus aureus, $\beta$-Heamolytic streptococcus, Shigella flexneri, Vibrio cholerae, Pseudomonas aeruginosa, and Klebsiella pneumonia. All the synthesized compounds are showing good zone of inhibition against the tested bacterial strains.
\end{abstract}

\section{Introduction}

Organic compounds with fluorine moiety are biologically very important [1-3]. Drug-receptor interactions are enhanced in the presence of small sized highly electronegative fluorine atom. The transport of drug is facilitated by the high lipophilicity of organofluorine compounds [4]. The occurrence of a fluorine substituent in commercial pharmaceutical compounds continues to increase by $2 \%$ in 1970 to estimates of more that $18 \%$ at present. The figures are higher (currently above 28\%) in agrochemicals [5]. In USA, 9 of 31 new drugs licensed in 2002 contained fluorine [6]. Thus, it can be conservatively estimated that globally about $20-25 \%$ of drugs in the pharmaceutical pipeline contain at least one fluorine atom. This is a high frequency considering organofluorine compounds are virtually absent as natural products, the traditional source of bioactives [7]. The very special effects of fluorine have proven difficult to divine in detail, and the high frequency of the element in small molecule bioactives has generally arisen from intense structure-activity relationship (SAR) studies, rather than rational predictive outcomes [8].
Of course some of the effects of fluorine substitution are relatively straightforward to interpret in that the fluorine substituent, when strategically positioned, can suppress adventitious metabolism, relative to the hydrocarbon analogue. However, it is never easy to predict the influence of fluorine substitution on the overall pharmacokinetic in a given situation. This remains a trial and error process. The importance of organofluorine compounds in medicinal chemistry continues to stimulate interest in the origins of the more cryptic effects of fluorine introduction. For example, now the availability of extensive X-ray data of small molecule interactions with proteins has begun to reveal generic stabilizing interactions between the $\mathrm{C}-\mathrm{F}$ bond and the protein, which improve our understanding of the predictable influence of fluorine incorporation $[9,10]$. The development of pharmacological agents able to counteract the mechanisms of drug resistance in oncology has remained a major goal for the past two decades. Fluorinated organic molecules are known to perform a wide range of biological functions [11].

The most widely used prodrugs such as 5-fluorouracil, floxuridine, ftorafur, and Camofur were converted to 
<smiles>O=c1[nH]cc(F)c(=O)[nH]1</smiles>

5-Fluorouracil<smiles>CCO[C@H]1CCOCC1n1cc(F)c(=O)[nH]c1=O</smiles><smiles>O=c1[nH]c(=O)n([C@@H]2C[C@H](O)[C@@H](CO)O2)cc1F</smiles><smiles>CCCCCOC(=O)n1cc(F)c(=O)[nH]c1=O</smiles>

Camofur

Floxuridine

FIGURE 1: The most widely used prodrugs contains fluorine atoms.

bioactive in vivo [12] (Figure 1). Fluorinated compounds were also widely used for the treatment of mestastic prostate cancer [13].

Curcumin, a well-known acyclic diarylheptanoid, has been identified as the major constituent in turmeric, and it has been known for some time that curcuminoids have been used as a natural food additive. It belongs to the group of $\beta$ diketones and exhibits tautomerism between enol- and ketostructures. It has attracted special attention due to its potent pharmacological activities such as protecting cells from $\beta$ amyloid insult in Alzheimer's disease [14] and cancer preventive properties [15]. Biological activities of curcumin chelated to metal ions as well as antioxidant effects of curcumin are also well documented in the literature $[16,17]$. The enol form is characterized by a strong intramolecular hydrogen bond. When the enol group forms the intramolecular hydrogen bond, the $\beta$-diketone undergoes changes towards the total $\pi$-system delocalization [18]. There is a strong correlation between the $\pi$-system delocalization and the strengthening of the intramolecular hydrogen bond. Moreover, in solution curcumin can form intermolecular $\mathrm{H}$-bonds with the solvent molecules, and this strongly influences its physicochemical properties. The chemopreventive effects of curcumin have been attributed to various biological properties, including neutralization of carcinogenic free radicals [19] and antiangiogenesis action, which limits the blood supply to rapidly grow malignant cells $[20,21]$. However, the nature of many biological properties of curcumin remains unclear; therefore the investigation of the structure and reactivity of this prolific medicinal agent is important. A photolysis study by Jovanovic et al. attributes the antioxidant mechanism of curcumin to intramolecular $\mathrm{H}$-atom in the keto-enolic group [22]. A theoretical study by Balasubramanian suggests that the ketoenolic form of curcumin may be responsible for the inhibition of $\beta$-amyloid aggregation [23].

\section{Experimental Methods}

2.1. General Procedures. Microwave irradiation is performed by a scientific microwave oven (model ELACTRO WAVE 1). The infrared spectra are recorded on a Thermo NicoletAvatar-330 FT-IR spectrophotometer using $\mathrm{KBr}$ pellets, and noteworthy absorption values $\left(\mathrm{cm}^{-1}\right)$ are obtained. ${ }^{1} \mathrm{H}$ and ${ }^{13} \mathrm{C}$ NMR spectra are recorded at $293 \mathrm{~K}$ on Bruker AMX400 spectrometer operating with the frequencies of $400 \mathrm{MHz}$ and $100 \mathrm{MHz}$, respectively, using $\mathrm{CDCl}_{3}$ as solvent. Samples are prepared by dissolving about $5 \mathrm{mg}$ of sample in $0.5 \mathrm{~mL}$ of $\mathrm{CDCl}_{3}$. All the chemical shift values are referenced to TMS. The mass spectra are recorded on a Varian Saturn 2200 MS spectrometer.

2.2. Experimental Procedure for Green Synthesis of Curcumin Analogues. To a mixture of appropriate benzaldehyde $(0.002 \mathrm{M})$ and acetyl acetone $(0.001 \mathrm{M})$ in a $50 \mathrm{~mL}$ borosil beaker, calcium oxide $(20 \mathrm{mg})$ was added. The reaction mixture was mixed properly with the help of a glass rod ( $5 \mathrm{sec}$ ) and then irradiated in a microwave oven for 60-120 sec at $160 \mathrm{~W}$ (monitored by TLC). The reaction mixture was removed from the oven and cooled and $2 \%$ hydrochloric acid $(10 \mathrm{~mL})$ was added and kept overnight. Then the reaction mixture was shaken well with ethyl acetate $(3 \times 10 \mathrm{~mL})$, and the catalyst was removed by filtration. The filtrate was concentrated in vacuum to afford the products 1-5.

2.3. In Vitro Antibacterial Activity. Nutrient broth was used to cultivate bacteria. Agar media was prepared by adding $24 \% \mathrm{w} / \mathrm{v}$ agar in the nutrient broth for making agar slants. Bacteria were subcultured on the nutrient agar slants. The inoculum was prepared by transferring loopful of the corresponding organism from the stock culture into the sterile broth and incubated at $37^{\circ} \mathrm{C}$ for bacterial strains. $20 \mathrm{~mL}$ of sterile nutrient agar media was added to each petri dish, and $2 \mathrm{~mL}$ of $24 \mathrm{~h}$ broth culture of bacteria was then added to the respective plates and mixed thoroughly by rotatory motion of the plates. The respective test compounds were dissolved in water:DMSO $(8: 2)$ in the concentration of $10 \mathrm{mg} / \mathrm{mL}$. This solution was maintained as a stock solution. The different concentrations (100, 200, and $500 \mathrm{ppm}$ ) were prepared from the stock solution. Sterile paper disc of $5 \mathrm{~mm}$ diameter was saturated with the three different concentrations, and such discs were placed in each seeded agar plates. The petri plates were incubated at $37^{\circ} \mathrm{C}$, and the zone of inhibitions were measured excluding the diameters of the paper disc $(5 \mathrm{~mm})$. Control discs were performed with sterile water. The inhibitory activities were compared with standard antibacterial drug ciprofloxacin. 
<smiles>[R3]c1c([R3])c(C=O)c([R3])c(C=O)c1[R]</smiles>

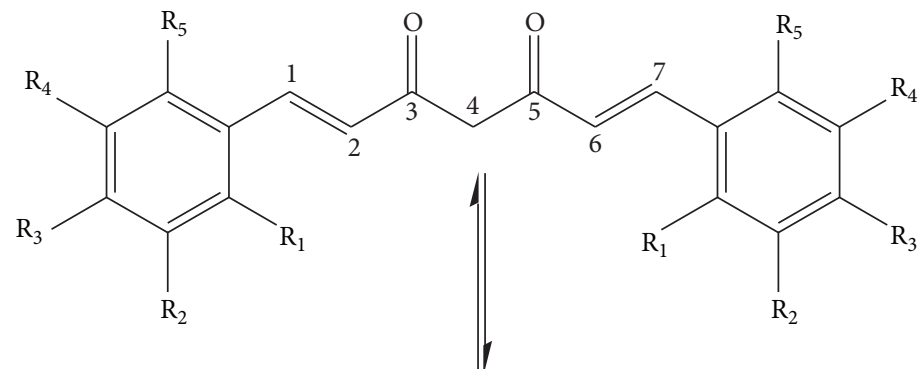

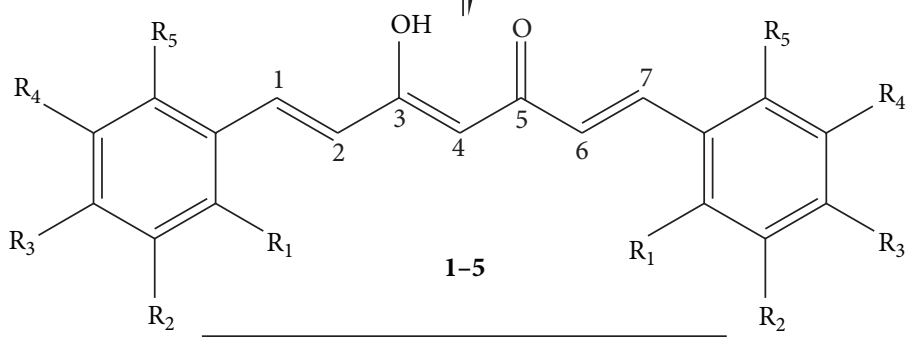

\begin{tabular}{cccccc}
\hline Compound & $\mathrm{R}_{1}$ & $\mathrm{R}_{2}$ & $\mathrm{R}_{3}$ & $\mathrm{R}_{4}$ & $\mathrm{R}_{5}$ \\
\hline $\mathbf{1}$ & $\mathrm{F}$ & $\mathrm{H}$ & $\mathrm{H}$ & $\mathrm{H}$ & $\mathrm{H}$ \\
$\mathbf{2}$ & $\mathrm{F}$ & $\mathrm{F}$ & $\mathrm{H}$ & $\mathrm{H}$ & $\mathrm{H}$ \\
$\mathbf{3}$ & $\mathrm{F}$ & $\mathrm{H}$ & $\mathrm{F}$ & $\mathrm{H}$ & $\mathrm{H}$ \\
$\mathbf{4}$ & $\mathrm{H}$ & $\mathrm{F}$ & $\mathrm{F}$ & $\mathrm{H}$ & $\mathrm{H}$ \\
$\mathbf{5}$ & $\mathrm{H}$ & $\mathrm{F}$ & $\mathrm{H}$ & $\mathrm{F}$ & $\mathrm{H}$ \\
\hline
\end{tabular}

SCHEme 1: Synthetic route for the synthesis of fluoro-substituted curcumins (1-5).

\section{Result and Discussion}

3.1. Chemistry. Compared to traditional methods, microwave synthesis is more convenient to synthesize and can be carried out in higher yields in short reaction times under mild reaction conditions. The catalyst calcium oxide is very cheaper, and we can reuse this catalyst for several cycles. The curcumin analogues (1-5) are synthesized in excellent yields by the reaction of acetylacetone with appropriate aldehydes catalyzed by activated calcium oxide under microwave irradiation within 60-120 sec (Scheme 1). The reaction time, the yields, and the melting points of the synthesized products are given in Table 1 . The structures of the all synthesized compounds (1-5) are confirmed by FT-IR, ${ }^{1} \mathrm{H}$ NMR, ${ }^{13} \mathrm{C}$ NMR, mass spectral studies, and elemental analysis.

In order to determine the structures of the synthesized compounds, compound 1 (1E,4Z,6E)-1,7-bis(2-fluorophenyl)-5-hydroxyhepta-1,4,6-trien-3-one is taken as the<smiles>O=C(C=Cc1ccccc1F)C=C(O)C=Cc1ccccc1F</smiles>

FIGURE 2: Structure of representative compound $\mathbf{1 .}$

representative compound (Figure 2), and the FT-IR, mass, ${ }^{1} \mathrm{H}$, and ${ }^{13} \mathrm{C}$ are shown in (Figure 3 ).

3.1.1. Infrared Spectroscopy. The FT-IR spectrum of compound 1 (1E,4Z,6E)-1,7-bis(2-fluorophenyl)-5-hydroxyhepta1,4,6-trien-3-one shows characteristic absorption frequencies around $3073-3002 \mathrm{~cm}^{-1}$ due to aromatic $\mathrm{CH}$ stretching 


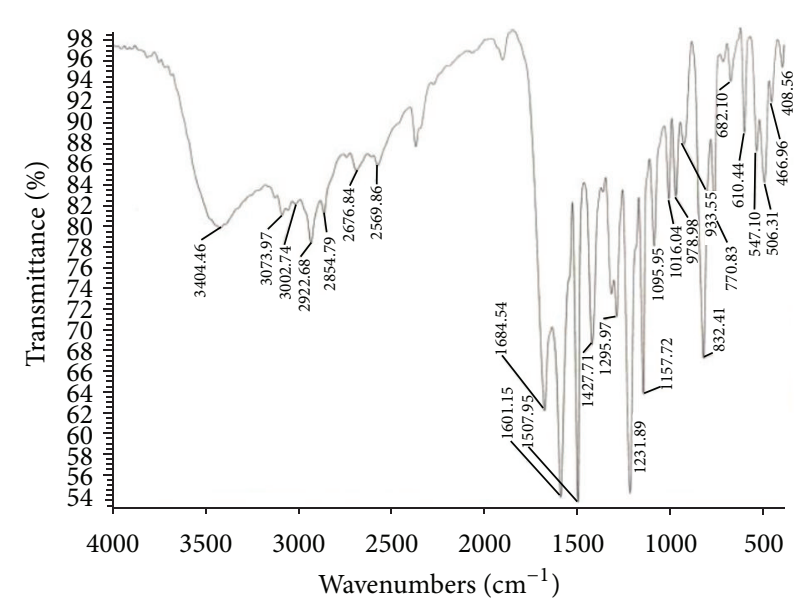

(a)

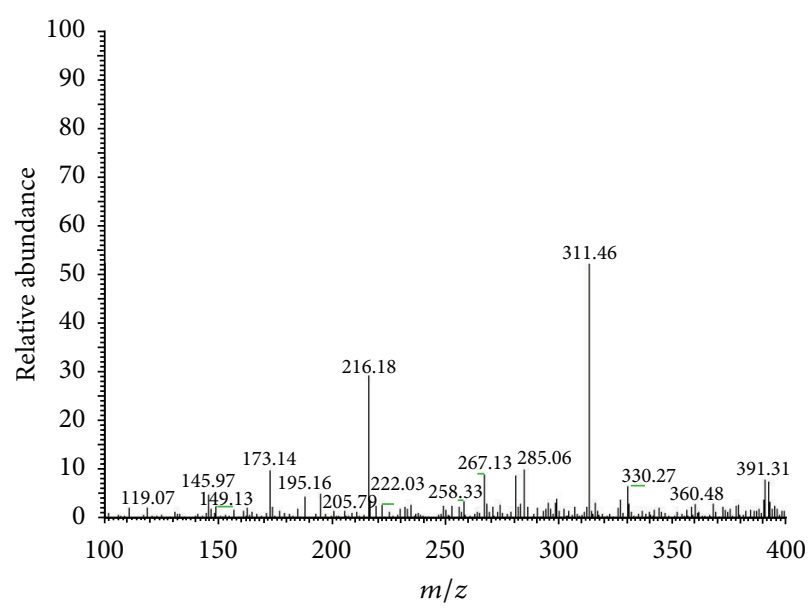

(b)

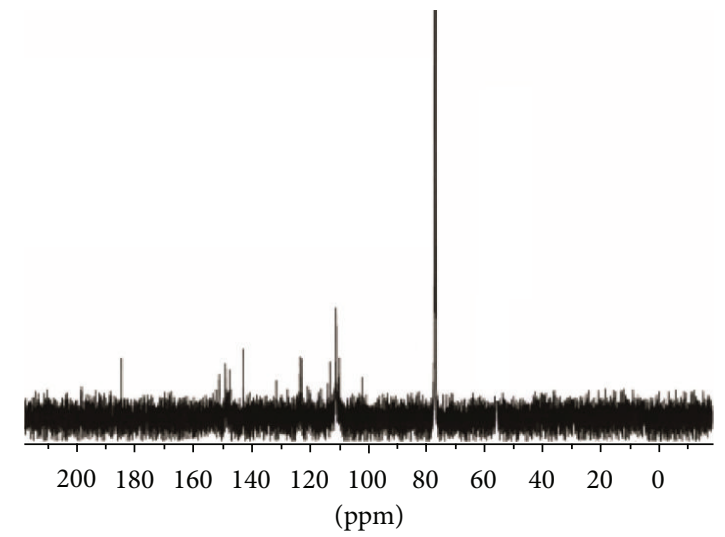

(d)

Figure 3: (a) FT-IR, (b) mass, (c) ${ }^{1} \mathrm{H}$, and (d) ${ }^{13} \mathrm{C}$ spectra of representative compound 1.

TABle 1: Physical and analytical data of curcumin analogues 1-5.

\begin{tabular}{lccccccc}
\hline Compound & Time $(\mathrm{sec})$ & Yield (\%) & Melting point $\left({ }^{\circ} \mathrm{C}\right)$ & \multicolumn{2}{c}{ Elemental analysis $(\%)$} \\
$\mathrm{C}$ found & & $\begin{array}{c}\mathrm{H} \text { found } \\
\text { (calculated) }\end{array}$ & $\begin{array}{l}\mathrm{m} / z(\mathrm{M}-\mathrm{H})^{+\bullet}, \\
\text { molecular formula }\end{array}$ \\
\hline $\mathbf{1}$ & 90 & 82 & $219-221$ & $72.70(73.07)$ & $4.48(4.52)$ & $311, \mathrm{C}_{19} \mathrm{H}_{14} \mathrm{~F}_{2} \mathrm{O}_{2}$ \\
$\mathbf{2}$ & 60 & 88 & $250-253$ & $65.30(65.52)$ & $3.42(3.47)$ & $347, \mathrm{C}_{19} \mathrm{H}_{12} \mathrm{~F}_{4} \mathrm{O}_{2}$ \\
$\mathbf{3}$ & 120 & 92 & $260-264$ & $65.30(65.52)$ & $3.42(3.47)$ & $347, \mathrm{C}_{19} \mathrm{H}_{12} \mathrm{~F}_{4} \mathrm{O}_{2}$ \\
$\mathbf{4}$ & 120 & 94 & $253-255$ & $65.30(65.52)$ & $3.42(3.47)$ & $347, \mathrm{C}_{19} \mathrm{H}_{12} \mathrm{~F}_{4} \mathrm{O}_{2}$ \\
$\mathbf{5}$ & 90 & 85 & $265-267$ & $65.30(65.52)$ & $3.42(3.47)$ & $347, \mathrm{C}_{19} \mathrm{H}_{12} \mathrm{~F}_{4} \mathrm{O}_{2}$ \\
\hline
\end{tabular}

vibrations. The absorption bands around $2922-2854 \mathrm{~cm}^{-1}$ are due to the aliphatic $\mathrm{CH}$ stretching vibrations. The absorption band at $3404 \mathrm{~cm}^{-1}$ is assigned to $\mathrm{OH}$ stretching vibration. The absorption band at $1684 \mathrm{~cm}^{-1}$ is assigned to carbonyl stretching vibration. The absorption frequency at $1601 \mathrm{~cm}^{-1}$ is attributed to the aliphatic $\mathrm{C}=\mathrm{C}$ stretching vibration. The FT-IR stretching frequencies of all the curcumin analogues reported here are listed in Table 2.
3.1.2. Analysis of ${ }^{1} H$ NMR Spectra. The assignments of signals have been done based on total widths, spin multiplicities, and by comparison with the reported literature values [2426]. In the ${ }^{1} \mathrm{H}$ NMR spectrum of compound 1 (1E,4Z,6E)-1,7bis(2-fluorophenyl)-5-hydroxyhepta-1,4,6-trien-3-one, a singlet observed at $5.21 \mathrm{ppm}$ is due to the presence of methine proton at H-4. A doublet that appeared at 6.54 and 7.60 is due to H-2 and H-6 protons, respectively. Whereas the doublet at 
TABLE 2: FT-IR stretching frequencies for selected functional groups and UV-vis absorption band of curcumin analogues 1-5.

\begin{tabular}{|c|c|c|c|c|c|}
\hline \multirow[b]{2}{*}{ Compound } & \multicolumn{5}{|c|}{ FT-IR stretching frequencies $\mathrm{cm}^{-1}$} \\
\hline & $-\mathrm{OH}$ & $>\mathrm{C}=\mathrm{O}$ & $\begin{array}{c}\text { Aliphatic } \\
\mathrm{C}=\mathrm{C}\end{array}$ & $\begin{array}{c}\text { Aromatic } \\
-\mathrm{C}-\mathrm{H}\end{array}$ & $\begin{array}{c}\text { Aliphatic } \\
-\mathrm{C}-\mathrm{H}\end{array}$ \\
\hline 1 & 3404 & 1684 & 1601 & 3073 & 2922,2854 \\
\hline 2 & 3501 & 1698 & 1619 & 3057 & 2925,2854 \\
\hline 3 & 3426 & 1698 & 1612 & 3080 & 2925,2855 \\
\hline 4 & 3481 & 1700 & 1609 & 3062 & 2923,2860 \\
\hline 5 & 3488 & 1705 & 1621 & 3088 & 2925,2849 \\
\hline
\end{tabular}

TABle 3: Proton NMR chemical shift ( $\delta$, ppm) data of curcumin analogues 1-5.

\begin{tabular}{lccccccc}
\hline Compound & H-1 $(\mathrm{d})$ & H-2 $(\mathrm{d})$ & OH-3 $(\mathrm{s})$ & H-4 (s) & H-6 (d) & H-7 (d) & Ar-H's (m) \\
\hline $\mathbf{1}$ & 6.38 & 6.54 & 10.52 & 5.21 & 7.60 & 7.75 & $7.45-6.90$ \\
$\mathbf{2}$ & 6.35 & 6.52 & 10.46 & 5.15 & 7.58 & 7.74 & $7.29-6.81$ \\
$\mathbf{3}$ & 6.34 & 6.51 & 10.42 & 5.17 & 7.59 & 7.74 & $7.26-6.79$ \\
$\mathbf{4}$ & 6.35 & 6.54 & 10.48 & 5.16 & 7.61 & 7.76 & $7.28-6.81$ \\
$\mathbf{5}$ & 6.37 & 6.53 & 10.47 & 5.15 & 7.59 & 7.75 & $7.30-6.79$ \\
\hline
\end{tabular}

6.38 and 7.75 is due to $\mathrm{H}-1$ and $\mathrm{H}-7$ protons. The aromatic protons appeared in the region of $7.45-6.90 \mathrm{ppm}$. All the proton NMR chemical shifts $(\delta$, ppm) of compounds $\mathbf{1}-\mathbf{5}$ are given in Table 3.

3.1.3. Analysis of ${ }^{13} C N M R$ Spectra. In the ${ }^{13} \mathrm{C}$ NMR spectrum of (1E,4Z,6E)-1,7-bis(2-fluorophenyl)-5-hydroxyhepta1,4,6-trien-3-one, the ${ }^{13} \mathrm{C}$ resonance at $102.86 \mathrm{ppm}$ is due to the presence of $\mathrm{C}-4$ carbon. The two carbon resonances observed at 126.67 and $126.38 \mathrm{ppm}$ are due to C-2 and C6 carbons, respectively. The other two carbon resonances observed at 135.91 and $145.96 \mathrm{ppm}$ are due to $\mathrm{C}-1$ and $\mathrm{C}$ 7 carbons, respectively. The ${ }^{13} \mathrm{C}$ resonances at 182.81 and 182.94 ppm correspond to the carbonyl carbons at C-3 and C5 , respectively. The aromatic ipso carbons appeared at 157.63 and $131.82 \mathrm{ppm}$ whereas the other aromatic carbons resonated in the range of 130.87-112.97 ppm. All the carbon NMR chemical shifts $(\delta, \mathrm{ppm})$ of compounds $\mathbf{1}-\mathbf{5}$ are given in Table 4 .

3.1.4. Mass Spectral and Elemental Analyses. Mass spectrum of compound 1 shows molecular ion peak at $m / z 311$ (M$\mathrm{H}^{+\bullet}$ ) by the loss of one proton which is consistent with the proposed molecular mass of compound $\mathbf{1}$.

Elemental analyses of compound $\mathbf{1}\left(\mathrm{C}_{\mathrm{cal}} 73.07, \mathrm{C}_{\mathrm{obs}} 72.70\right.$; $\mathrm{H}_{\text {cal }}$ 4.52, $\left.\mathrm{H}_{\mathrm{obs}} 4.48\right)$ are consistent with the proposed molecular formula $\left(\mathrm{C}_{19} \mathrm{H}_{14} \mathrm{~F}_{2} \mathrm{O}_{2}\right)$ of compound 1 . Mass spectral and elemental analysis data of all the compounds are given in Table 1.

\subsection{In Vitro Antibacterial Activity}

3.2.1. Disc Diffusion Method. All the curcumin analogues (1-5) are tested for their antibacterial activity by disc diffusion method against clinically isolated bacterial strains such as Staphylococcus aureus, $\beta$-Heamolytic streptococcus, Shigella flexneri, Vibrio cholerae, Pseudomonas aeruginosae, and Klebsiellae pneumonia. All the curcumin analogues show moderate to excellent activity against the tested bacterial strains, but their activity decreases upon dilution. The inhibitory activities were compared with the commercial bactericide, namely, Ciprofloxacin, under similar conditions.

3.2.2. Activity. A series of fluorine substituted symmetrical novel curcumin analogues were tested for their antibacterial activity by disc diffusion method, and their respective zone of inhibition against the tested bacterial strains was given in Table 5, and the representative photographs for disc diffusion method are reproduced in Figure 4. Compound 1 which has fluorine atom at the ortho-position of the phenyl rings revealed good zone of inhibition against Shigella flexneri and Pseudomonas aeruginosa. Compound 2 which has two fluorine atoms at the ortho- and meta-positions of the phenyl rings shows higher zone of inhibition against Shigella flexneri and shows moderate zone of inhibition against Staphylococcus aureus, Vibrio cholerae, and Klebsiella pneumonia. Compound 3 which has two fluorine atoms at the orthoand para-positions of the phenyl rings shows good zone of inhibition against Staphylococcus aureus, Shigella flexneri, Vibrio cholerae, and Pseudomonas aeruginosa. Compound 4 which has two fluorine atoms at the meta- and para-positions of the phenyl rings exerted superior zone of inhibition against Staphylococcus aureus and Pseudomonas aeruginosa and good zone of inhibition against $\beta$-Heamolytic streptococcus, Vibrio cholerae, and Klebsiella pneumonia. Compound 5 which has two fluorine atoms at the two meta positions of the phenyl rings shows good zone of inhibition against $\beta$-Heamolytic streptococcus and Pseudomonas aeruginosa.

\section{Conclusion}

A number of five fluorine substituted curcumin analogues have been synthesized in a cheaper and greener method using calcium oxide as catalyst under microwave irradiation. All the synthesized compounds have been characterized by FT-IR, 
TABLE 4: Carbon NMR chemical shift ( $\delta$, ppm) data of curcumin analogues 1-5.

\begin{tabular}{lccccccccc}
\hline Compound & C-1 & C-2 & C-3 & C-4 & C-5 & C-6 & C-7 & Ar-C's & Ipso carbons \\
\hline $\mathbf{1}$ & 135.91 & 124.67 & 182.81 & 102.86 & 182.94 & 126.38 & 145.96 & $130.87-112.97$ & $157.63,131.82$ \\
$\mathbf{2}$ & 136.52 & 125.69 & 183.64 & 103.97 & 183.82 & 127.57 & 146.82 & $127.23-115.59$ & $148.86,144.57$ \\
$\mathbf{3}$ & 136.91 & 125.81 & 183.93 & 104.35 & 184.12 & 127.96 & 147.21 & $131.09-105.26$ & $165.35,159.23,130.58$ \\
$\mathbf{4}$ & 136.26 & 125.31 & 183.28 & 103.76 & 183.59 & 127.48 & 146.38 & $130.29-108.67$ & $160.28,157.69,131.19$ \\
$\mathbf{5}$ & 135.59 & 124.69 & 182.76 & 102.97 & 182.94 & 126.25 & 145.69 & $130.18-107.52$ & $163.43,157.82,134.64$ \\
\hline
\end{tabular}

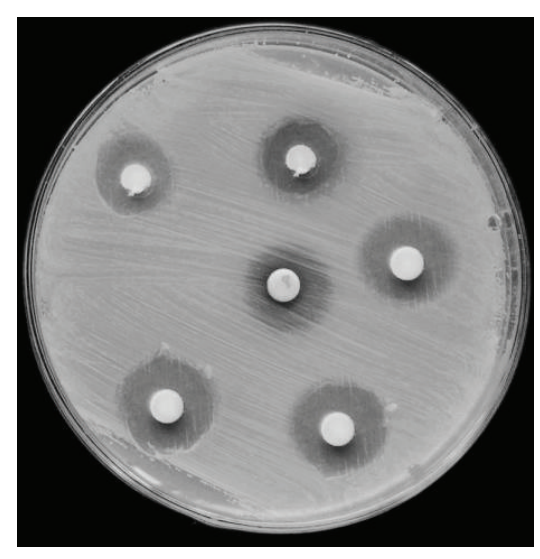

Staphylococcus aureus

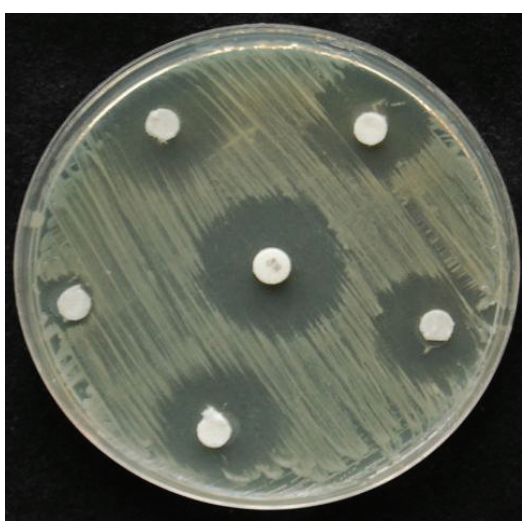

Shigella flexneri

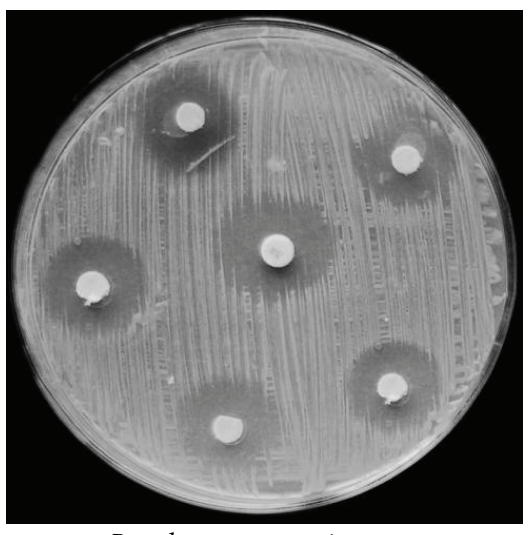

Pseudomonas aeruginosa

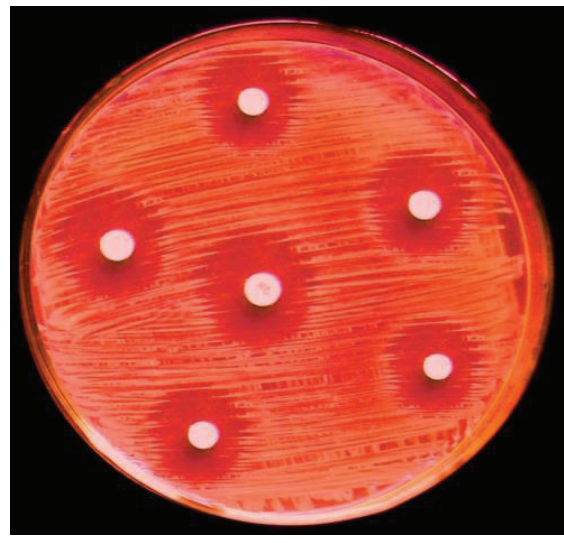

$\beta$-Heamolytic streptococcus

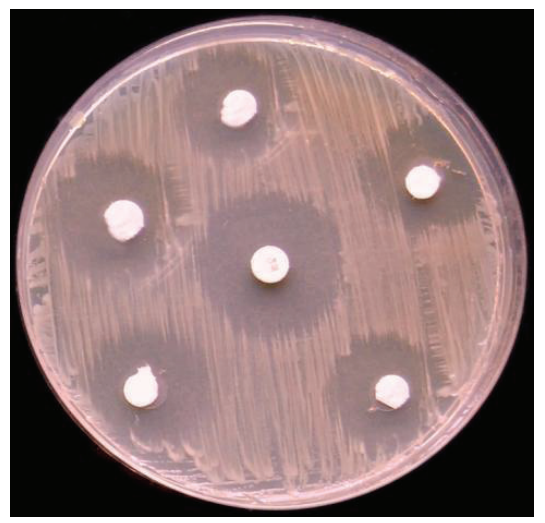

Vibrio cholerae

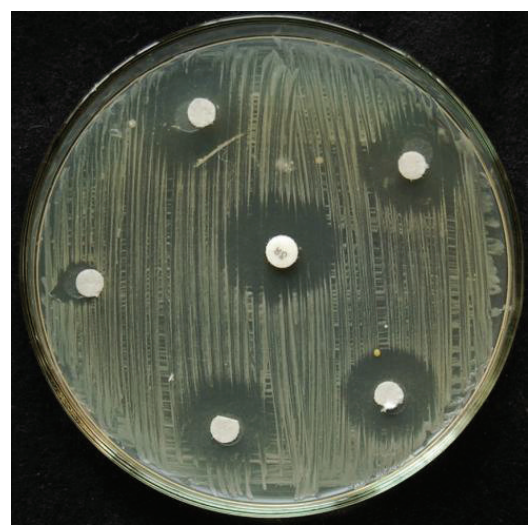

Klebsiella pneumonia

Figure 4: Representative photographs of disc diffusion method for compounds 1-5. 


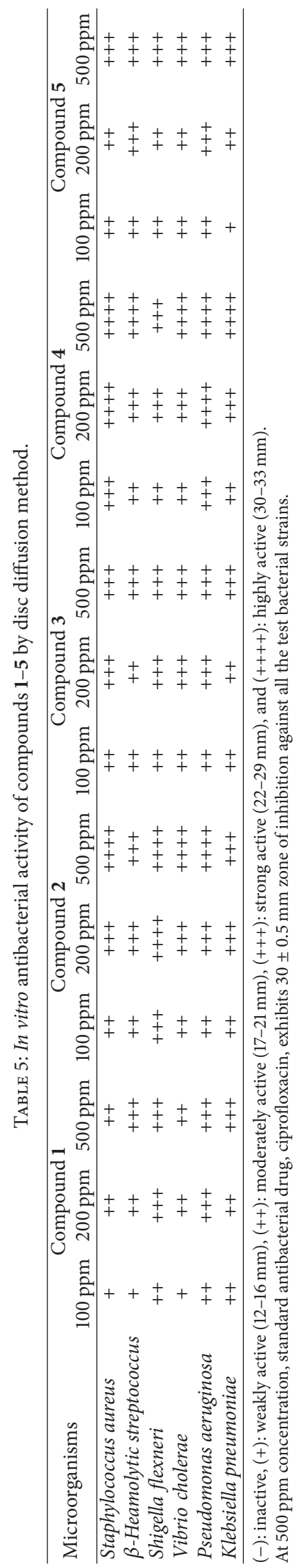


MS, elemental analysis and ${ }^{1} \mathrm{H}$ and ${ }^{13} \mathrm{C}$ NMR spectroscopic techniques and screened for their antibacterial activities against Staphylococcus aureus, $\beta$-Heamolytic streptococcus, Shigella flexneri, Vibrio cholerae, Pseudomonas aeruginosa, and Klebsiella pneumonia. All the synthesized compounds are showing good zone of inhibition against the tested bacterial strains.

\section{Acknowledgments}

The authors are thankful to the Department of Microbiology, Rajah Muthiah Medical College, Annamalai University, for the screening of antibacterial activities of the synthesized compounds. One of the authors, namely, S. Elavarasan, is thankful to CavinKare Research Centre, Chennai, for providing financial support in the form of Junior Research Fellowship.

\section{References}

[1] R. Filler, Y. Kobayasi, and L. M. Yagupolskii, Eds., Fluorine in Bioorganic Chemistry, Elsevier, Amsterdam, The Netherland, 1993.

[2] R. Filler, Fluorine Containing Drugs in Organofluorine Chemicals and TheirIndustrial Application, chapter 6, Pergamon, New York, NY, USA, 1979.

[3] M. Hudlicky, Chemistry of Organic Compounds, Ellis Horwood, Chichester, UK, 1992.

[4] M. Sharif, S. Reimann, A. Villinger, and P. Langer, "One-pot synthesis of difluorinated ortho-terphenyls by site-selective suzukimiyaura reactions of 1,2-dibromo-3,5-difluorobenzene," Synlett, no. 6, pp. 913-916, 2010.

[5] J. P. Bégué and D. Bonnet-Delpon, Chimie Bioorganique et Médicinal du Fluor, CNRS, Paris, France, 2005.

[6] H. Böhm, D. Banner, S. Bendels et al., "Fluorine in medicinal chemistry," ChemBioChem, vol. 5, no. 5, pp. 637-643, 2004.

[7] H. Deng, D. O’Hagan, and C. Schaffrath, "Fluorometabolite biosynthesis and the fluorinase from Streptomyces cattleya," Natural Product Reports, vol. 21, pp. 773-784, 2004.

[8] P. Kirsch, Modern Fluoroorganic Chemistry: Synthesis, Reactivity, Applications, Wiley-VCH, Weinheim, Germany, 2004.

[9] R. Paulini, K. Müller, and F. Diederich, "Orthogonal multipolar interactions in structural chemistry and biology," Angewandte Chemie, vol. 44, no. 12, pp. 1788-1805, 2005.

[10] J. A. Olsen, D. W. Banner, P. Seiler et al., "Fluorine interactions at the thrombin active site: protein backbone fragments $\mathrm{H}-\mathrm{C}_{\alpha}-\mathrm{C}=$ O comprise a favorable C-F environment and interactions of $\mathrm{C}$ F with electrophiles," ChemBioChem, vol. 5, no. 5, pp. 666-675, 2004.

[11] P. Cozzi, N. Mongelli, and A. Suarato, "Recent anticancer cytotoxic agents," Current Medicinal Chemistry, vol. 4, no. 2, pp. 93121, 2004.

[12] P. V. Danenberg, "Pharmacogenomics of thymidylate synthase in cancer treatment," Frontiers in Bioscience, vol. 9, pp. 24842494, 2004.

[13] V. A. Nair, S. M. Mustafa, M. L. Mohler, S. J. Fisher, J. T. Dalton, and D. D. Miller, "Synthesis of novel iodo derived bicalutamide analogs," Tetrahedron Letters, vol. 45, no. 51, pp. 9475-9477, 2004.
[14] S.-Y. Park and D. S. H. L. Kim, "Discovery of natural products from Curcuma longa that protect cells from beta-amyloid insult: a drug discovery effort against Alzheimer's disease," Journal of Natural Products, vol. 65, no. 9, pp. 1227-1231, 2002.

[15] J. Ishida, H. Ohtsu, Y. Tachibana et al., "Antitumor agents, part 214: synthesis and evaluation of curcumin analogues as cytotoxic agents," Bioorganic and Medicinal Chemistry, vol. 10, no. 11, pp. 3481-3487, 2002.

[16] Y. Jiao, J. Wilkinson, E. C. Pietsch et al., "Iron chelation in the biological activity of curcumin," Free Radical Biology and Medicine, vol. 40, no. 7, pp. 1152-1160, 2006.

[17] L. Shen, Z. Hong-Yu, and J. Hong-Fang, "Ab initio study ground-state potential energy function of SiCl," Journal of Molecular Structure, vol. 728, pp. 159-162, 2005.

[18] G. Gilli and V. Bertolasi, "Structural chemistry of enols," in The Chemistry of Enols, Z. Rppoport, Ed., pp. 713-764, John Wiley \& Sons, New York, NY, USA, 1990.

[19] S. V. Jovanovic, C. W. Boone, S. Steenken, M. Trinoga, and R. B. Kaskey, "How curcumin works preferentially with water soluble antioxidants," Journal of the American Chemical Society, vol.123, no. 13, pp. 3064-3068, 2001.

[20] D. Thaloor, A. K. Singh, G. S. Sidhu, P. V. Prasad, H. K. Kleinman, and R. K. Maheshwari, "Inhibition of angiogenic differentiation of human umbilical vein endothelial cells by curcumin," Cell Growth and Differentiation, vol. 9, no. 4, pp. 305312, 1998.

[21] J. L. Arbiser, N. Klauber, R. Roghan et al., "Curcumin is an in vivo inhibitor of angiogenesis," Molecular Medicine, vol. 4, no. 6, pp. 376-383, 1998.

[22] S. V. Jovanovic, S. Steenken, C. W. Boone, and M. G. Simic, "H-atom transfer is a preferred antioxidant mechanism of curcumin," Journal of the American Chemical Society, vol. 121, no. 41, pp. 9677-9681, 1999.

[23] K. Balasubramanian, "Molecular orbital basis for yellow curry spice curcumin's prevention of Alzheimer's disease," Journal of Agricultural and Food Chemistry, vol. 54, no. 10, pp. 3512-3520, 2006.

[24] A. N. Nurfina, M. S. Reksohadprodjo, H. Timmerman, U. A. Jenie, D. Sigiyanto, and H. Vanderhoot, "Synthesis of some symmetrical curcumin derivatives and their antiinflammatory activity," European Journal of Medicinal Chemistry, vol. 32, no. 4, pp. 321-328, 1997.

[25] W. M. Weber, L. A. Hunsaker, S. F. Abcouwer, L. M. Deck, and D. L. van der Jagt, "Anti-oxidant activities of curcumin and related enones," Bioorganic and Medicinal Chemistry, vol. 13, no. 11, pp. 3811-3820, 2005.

[26] S. Venkateswarlu, M. S. Ranachandra, and G. V. Subburaju, "Synthesis and biological evaluation of polyhydroxycurcuminoids," Bioorganic \& Medicinal Chemistry, vol. 13, pp. 63746380, 2005. 

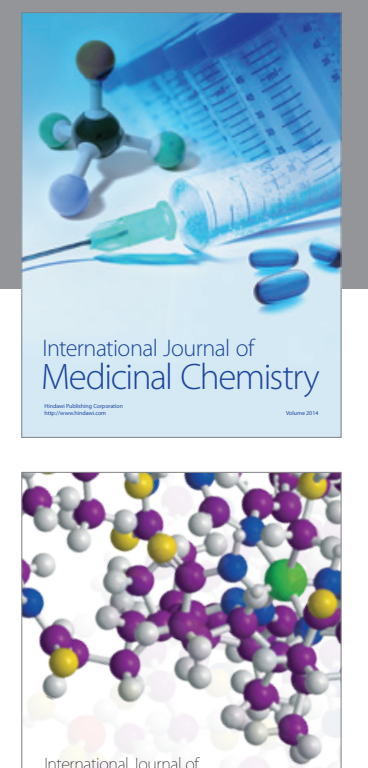

\section{Carbohydrate} Chemistry

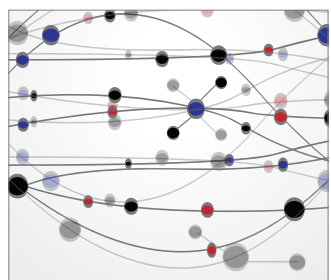

The Scientific World Journal
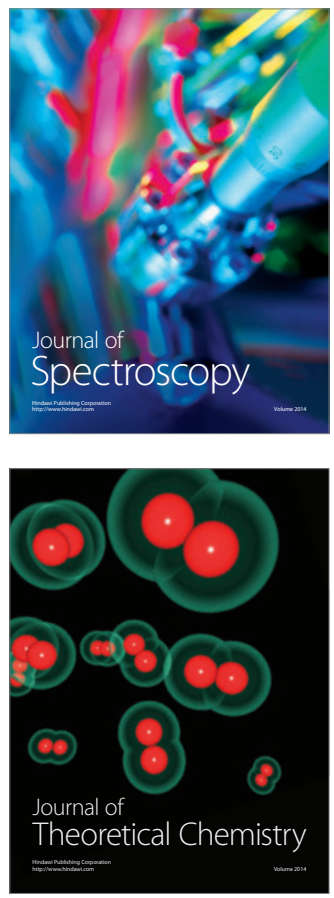
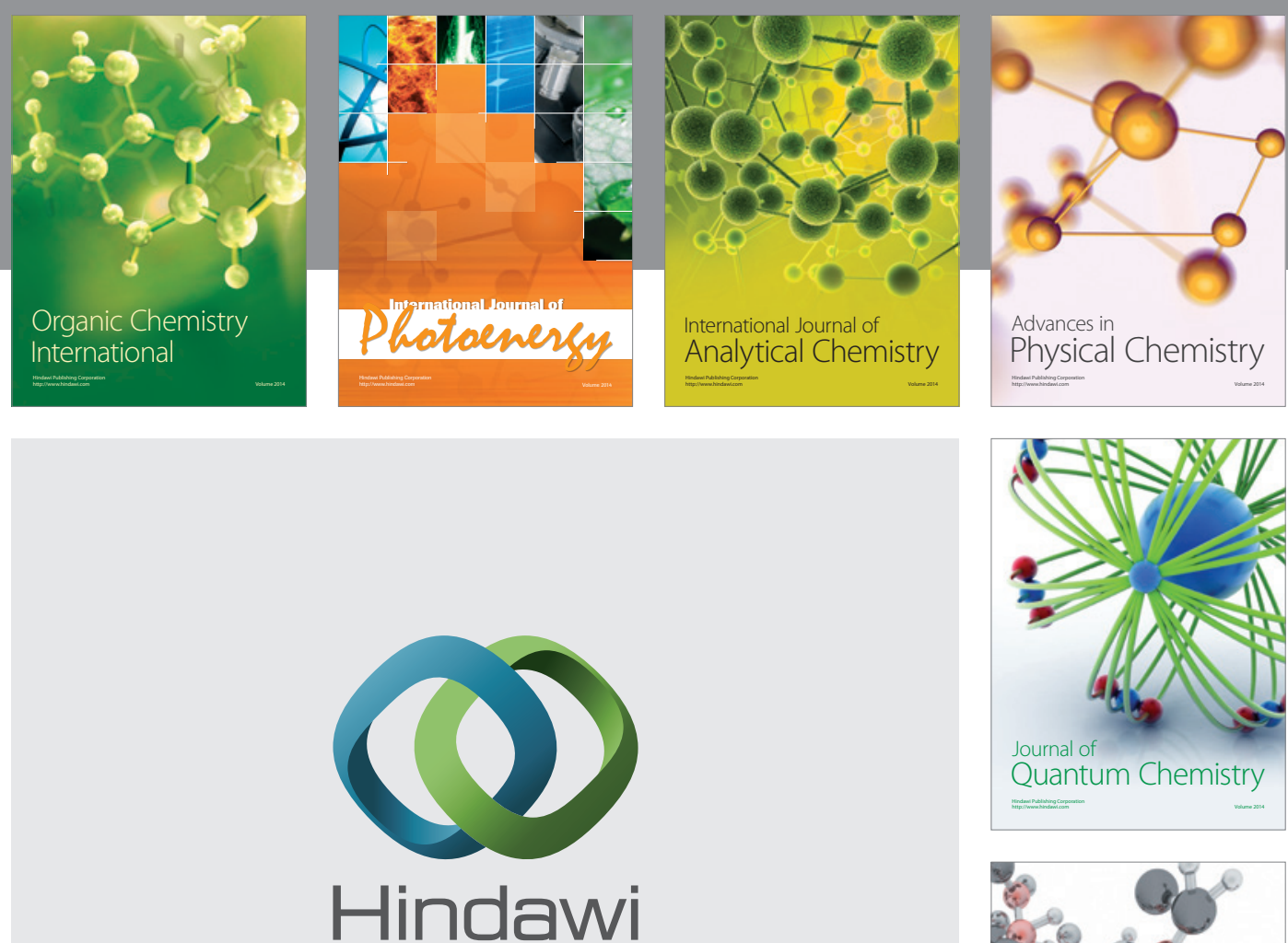

Submit your manuscripts at

http://www.hindawi.com

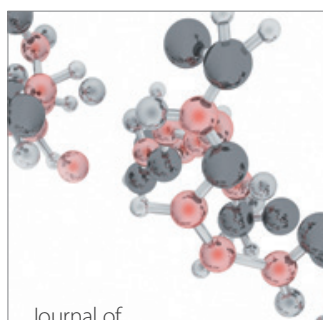

Analytical Methods

in Chemistry

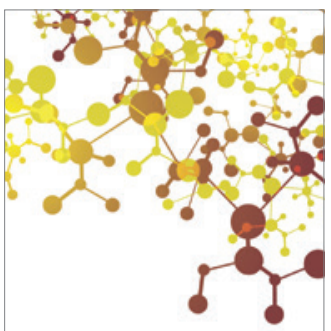

Journal of

Applied Chemistry

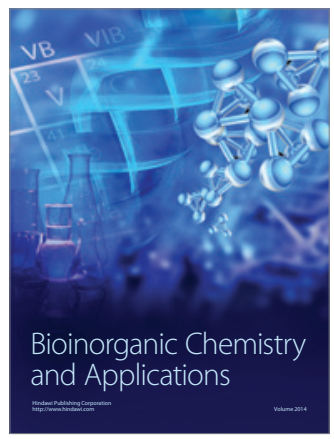

Inorganic Chemistry
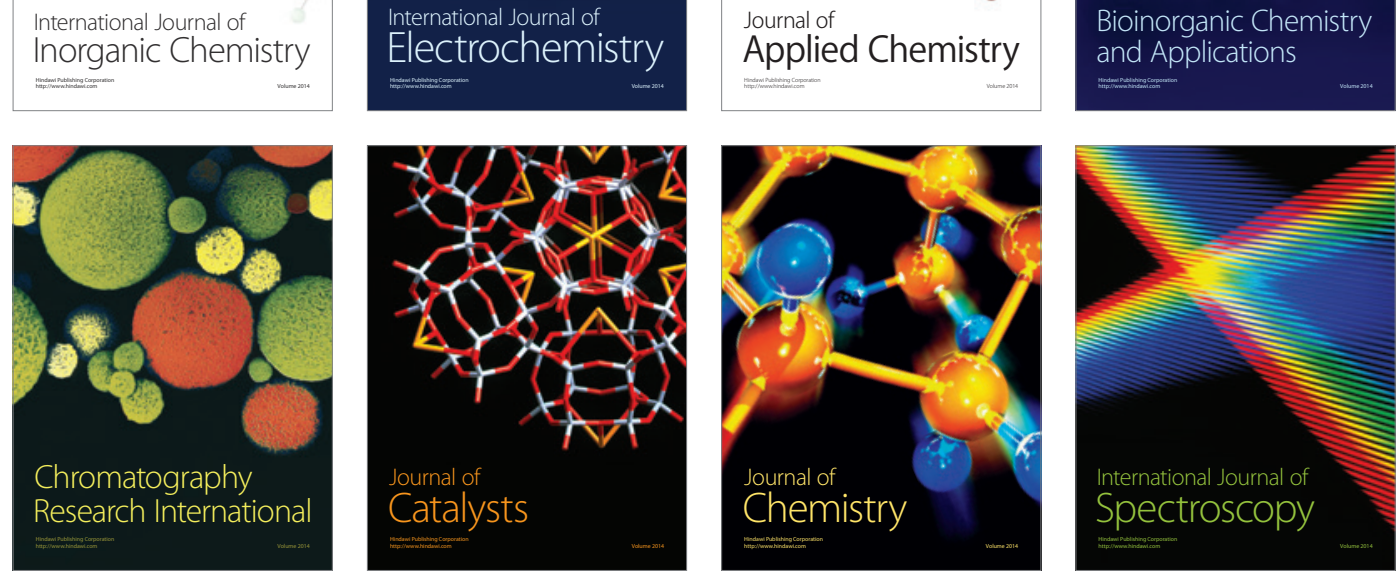